\title{
Horticultural Research in Kenya
}

\author{
H. Kaburu M'Ribu' ${ }^{1}$ P. Lanny Neel ${ }^{2}$, and Thomas A. Fretz ${ }^{3}$ \\ Department of Horticulture, Egerton University, Box 536, Njoro, Kenya
}

Kenya is a tropical East African nation with a wide diversity of climatic and geographical regions. This diversity allows many horticultural crops to be introduced and grown successfully. Horticultural production has contributed significantly to the Kenyan economy in the past decade, and it will continue to do so. This paper attempts to summarize significant horticultural events and research in Kenya and describe possible future developments.

\section{Historical developments}

The earliest recorded work on horticultural crops was in 1911, when a few tropical fruit were planted at the coastal Matuga Station [45 $\mathrm{m}$ above sea level (ASL)]. Various fruit and vegetable species from Europe and other parts of the world were introduced later. In 1920, apples (Malus domestics Borkh.), persimmons (Diospyrus kaki L.f.), plums (Prunus sp.), and avocados (Persea americana C.F. Gaertn.) were imported from South Africa and planted at Kabete (1737 m ASL), near Nairobi. Agricultural research for the (then) colony was centered in Nairobi at the Scott Agricultural Laboratories, now named the National Agricultural Laboratories. Many research programs were moved from Nairobi to other sites in 1927, when the coastal station turned its focus to tropical fruits and warm- and hot-season vegetables, among other crops. Work on temperate-zone (TZ) fruits and cool-season vegetables was moved to higher elevations. A systematic plant introduction service was begun in 1931 to facilitate introducing and testing many crop species and cultivars (Kenya Dept. of Agriculture, 1933).

A few TZ fruits were planted on an experimental site at Tigoni (2100 m ASL), in the central highlands near Nairobi. In 1946, all such work was moved to the Molo Station (2550 m ASL) in the highlands west of the Rift Valley. This site has an annual mean of $14.4 \mathrm{C}$, but drops below 13C during the July-August cool season-a temperature low enough to

Received for publication 3 May 1993. Accepted for pubtication25June1993.JournalPaper no. J-15 171 of the Iowa Agriculture and Home Economics Experiment Station, Ames. Project no. 0150. We appreciate the assistance of the Kenya Agricultural Research Institute in providing some of the historical information noted in this article and Barbara Brownforherinvaluable work on earlier versions of this paper. The cost of publishing this paper was defrayed in part by the payment of page charges. Underpostal regulations, this paper therefore must be hereby marked advertisement solely to indicate this fact.

'Senior Lecturer.

${ }^{2}$ Associate Professor, Dept. of Plant and Earth Science, Univ. of Wisconsin, River Falls.

${ }^{3}$ AssociateDeanandDirector,IowaAgriculture and Home Economics Experiment Station, Iowa State Univ., Ames. satisfy chilling requirements of low-chilling TZ fruits. Additional fruit crop research was conducted at other stations located at medium elevations: apple and citrus at Kitale (1860 m ASL) in the western highlands and citrus, avocado, and fig (Ficus carica L.) at Ruiru (1670 $\mathrm{m}$ ASL) in the central highlands. In 1955, an irrigation research station opened at Perkerra (550 m ASL in the hot, arid northern Rift Valley) for studies on hot-season fruits and vegetables. Thus, when Kenya gained independence in 1963, several stations already had established horticultural research programs.

Soon after independence, all horticultural research was coordinated through the National Horticultural Research Station (NHRS) at Thika (1549 m ASL), $\approx 45 \mathrm{~km}$ northeast of Nairobi. The Thika station was established in 1957 for experiments on sisal (Agave sisalana Perrine) and pineapple [Ananas comosus (L.) Merrill]. Horticultural research activities were also included in the programs of several other stations throughout Kenya.

Since 1963, minimal horticultural research has been conducted, and it is often limited to client-oriented adaptive trials; e.g., cultivar adaptability, spacing requirements, propagation, production of planting materials, fertilizer and manure application, crop rotations, irrigation frequency, and chemical or cultural pest control. Only recently has there been interest in studying cropping systems, seed production methods, cultivar breeding, food technology, postharvest handling, and production economics.

The low overall importance of Kenya's horticultural industry in the past is one explanation for the slight emphasis on research. In the postindependence period, research on staple food products (maize and beans) was emphasized to ensure national food sufficiency; thus, horticulture (especially fruits and ornamentals) did not receive high priority. Because Kenya is a young, developing nation, there has been a shortage of qualified scientists, scientific literature, and well-equipped laboratories. Although the problem of insufficient literature and laboratory equipment still exists, the current emphasis on specialized personnel training, together with collaborative international assistance, is helping to alleviate the shortage of scientists.

\section{Tropical and subtropical fruits and nuts}

Mango (Mangifera indica L.), avocado, pineapple, passion fruit (Passiflora edulis Sims), and papaya (Carica papaya L.) are Kenya's most important export fruits. Banana (Musa acuminata Colla), plantain (M. paradisiaca L.), and citrus fruits are mainly eaten locally. Macadamia nut (Macadamia integrifolia Maiden \& Betche), coconut (Co$\cos$ nucifera L.), and cashew (Anacardium occidental L.) are grown for local and export markets.

Since the first citrus plants were established along Kenya's coast early in the 20th century, there has been continued interest in developing citrus production to meet local demand. As early as 1932, many stations had citrus nurseries for supplying budded trees. Sweet orange [Citrus sinensis (L.) Osbeck] is the most important citrus crop for the local market, while lime [C. aurantiifolia (Christm.) Swingle], lemon [C. limon (L.) Burro. f.], and grapefruit (C. $\times$ paradisi Macfady) are grown primarily for export. Citrus research, focusing on rootstock evaluation, propagation methods, cultivar trials, plant nutrition, and pest control, has been attempted at other stations located at a range of elevations. Citrus crops grown on the coast and at Perkerra had better growth, yield, and quality than those at higher, cooler elevations. Until 1985, the NHRS preserved a large collection of citrus and related species for future breeding work, but all the plants at this and other highland stations were destroyed when citrus greening became established in Kenya. This viral disease is vectored by the citrus psyllid (Trioza erytreae), which does not live at lowland (warm) locations. Consequently, all propagation and research work on citrus was moved to low-elevation stations.

Bananas have been grown in Kenya for many years, and various cultivars of cooking and ripening types have been evaluated. Most of the work has involved cultivar adaptability, fertilizer application, pruning, and insect pest control.

Fresh pineapple was the leading export fruit from Kenya until the 1970s, when Kenya lost its comparative advantage. Pineapple research was initiated at the coastal research station before 1954 and was later moved to the NHRS. Research is concentrated on cultivar adaptability, planting materials, spacing, fertilizer use, cropping cycles, mulching, and crop protection.

Avocado, papaya, and passion fruit are among the early introductions that grow well at many low and medium elevations in Kenya. Local demand for all three crops is low, but production has increased to accommodate the expanding export market. Research on avocado and passion fruit primarily has focused on spacing, fertilizer application, and disease control. At present, most work on these crops has been done at the NHRS, because their economic potential as exports has only recently become evident. Propagating avocado and pruning and trellising passion fruit have been well investigated, but little work has involved papaya.

Virtually no research has focused on mango in Kenya, even though the crop has been grown there for hundreds of years (Sharma, 
1980), likely because mangoes grow and produce well with minimal care. Most mangoes grow in the coastal region as scattered individual plants, sometimes in a semi-wild state. Because their commercial value increased rapidly in the 1980s, research was initiated recently, mainly in the coastal area. New and old cultivars, along with cultural and crop protection practices, are being evaluated at the coast and upcountry locations. Mangoes have good potential for development in Kenya's semiarid areas.

A farmer introduced macadamia nuts in 1946 in an adaptability trial. Since then, the crop has grown well at medium elevations $(\approx 1400$ to $1950 \mathrm{~m} \mathrm{ASL})$ in the coffee-growing regions. Propagation, spacing, fertilizer application, intercropping, and breeding studies have been conducted. Macadamias one of the few horticultural crops in Kenya with a breeding program to select cultivars for diverse microclimates.

Coconut and cashew are among the most important crops of the coastal strip. They are well adapted to this region and have been grown there for many centuries. The Portuguese introduced cashew in the 16th century, but coconut was a much earlier introduction. Research on these crops has focused on propagation, cultivar selection, field management, and pest control methods.

Other tropical/subtropical crops that have received attention are guava (Psidium guajava L.), date (Phoenix dactylifera L.), cherimoya (Annona cherimola Mill.), sugar apple (A. squamosa L.), white sapote (Casimeroa edulis Llave), tree tomato [Cyphomandra betacea (Cav.) Sendtn.], sapodilla [Manilkara zapota (L.) VanRoyen], breadfruit [Artocarpus altilis (Parkins.) Fosh.], and jackfruit (A. heterophyllus Lam.). Several guava cultivars have been grown at medium elevations, where wild plants may be found, but no systematic research program has been developed. Dates were established at Perkerra about 1955 and have performed well, but there has been no serious research on them. They grow well in hot, arid areas, and some plants have been established in irrigation trials in the northern part of the country: A few plants of other minor crops [e.g.; mangosteen (Garcinia mangostana L.), durian (Durio zibethinus J. Murr.), lychee (Litchi chinensis Sonn.)] that were introduced into Kenya as early as 1930 can be found growing in isolation in various parts of the country. In addition, some are grown as specimen plants at the NHRS. Systematic trials need to be performed to establish the potential of these crops.

\section{Temperate-zone fruits}

After the Molo station was established in 1946, TZ fruits received more attention than most other horticultural crops in an effort to provide fruit for European settlers. Several TZ fruit species were introduced and tested in Kenya's highland regions, and apples, plums, pears (Pyrus communis L.), and peaches [Prunus persica (L.) Batsch.] showed economic potential.
Research on TZ fruits was directed principally toward finding cultivars suitable for local growing conditions; e.g., those with minimal chilling conditions, resistance to disease pressures under high relative humidity, and -tolerance to adverse soil conditions (insufficient nutrients, nematodes, and diseases) —all factors that could be ameliorated with suitable rootstock/scion combinations. Additional work has included spacing requirements, fertilization, and propagation.

Apple cultivars found suitable for these growing conditions include 'Winter Banana' and 'Rome Beauty' (Erez, 1980)—two cultivars still widely grown in Kenya. The 'Methley' plum, grown mainly from cuttings, is the predominant plum cultivar in Kenya, but many other cultivars produce fairly well and are maintained at the Molo station. 'Kieffer' pear is virtually the only pear grown commercially in Kenya because of its high productivity, although it has poor eating quality. Peaches do not grow well in Kenya. Almond (Prunus dulcis Mill), apricot (P. armeniaca L.), walnut (Juglans regia L.), chestnut (Castanea crenata Siebold \& Zucc.), olive (Olea europaea L.), and quince (Cydonia oblongs Mill.) also were tested at Molo, but they lack economic potential.

The departure of European research scientists after independence brought the $\mathrm{TZ}$ fruit research program to a standstill around 1969, and the scientists who remained had inadequate knowledge of these fruits to continue the work. In addition, there was pessimism about what contribution $\mathrm{TZ}$ fruits could make to the economy of a newly independent Kenya. Nor were geographical factors favorable for TZ fruit cultivation. Some cultivars that initially seemed promising had generally poor yield due to insufficient chilling. Minimum temperatures often were not sufficiently low or did not last long enough, and chemical control of budbreak was unreliable. High relative humidity contributed to the spread of fungal diseases and to the development of lichens and parasitic plants (Erez, 1980). There have been attempts to revive the program, but these crops have not been given high priority because they are unknown locally, with consequent low local demand, and have little export potential. However, there are many possible growing areas in the country and local demand is increasing, so research on these crops recently has been expanded.

\section{Small fruits}

Strawberry (Fragaria xananassa Duch.), grape (Vitis vinifera L.), blackberry (Rubus spp.), youngberry ( $R$. ursinus Chain.), raspberry ( $R$. idaeus L. ), and cape gooseberry (Physalis peruviana L.) were tested at the Molo station during the colonial period. Grapes also were tested at Thika and Perkerra, and strawberries at Thika and Limuru. But, in general, research on small fruits has not been extensive, because of their perishable nature.

As with TZ fruits, research on small fruits has emphasized cultivar adaptability and production practices suitable for local conditions.
'Cambridge Favourite' is one of many British strawberry cultivars tested and still grown in Kenya. To obtain the best yield and quality, strawberry plants are deflowered for 6 to 8 months, then harvested for 2 to 3 months during the start of the long rainy season (AprilJune). Deflowering can be omitted if fruits are used for processing, when size is not important. This cycle can be repeated for 3 years before replanting is necessary. Punnets that hold $\approx 0.5 \mathrm{~kg}$ of strawberries and are covered with cellophane make satisfactory packaging for export. The export market for fresh strawberries is increasing, and research on strawberries is continuing.

Grapes grow well at medium and low elevations; however, bird damage and fungal diseases limit production. Most of the work has involved table grapes, since wine grapes are a recent introduction. With the exception of raspberry, berries (Rubus spp.) grew well, with good productivity and quality. Only small amounts are grown, however, because of limited processing capabilities and the crop's high perishability. Cape gooseberry yielded $\approx 25 \mathrm{t} \cdot \mathrm{ha}^{-1}$ in trials conducted in 1958-60, but production is limited.

\section{Vegetables}

Vegetable species have been tested in the various ecological zones of Kenya, but, in most cases, only a few cultivars are grown. Research during the colonial era consisted mainly of testing various species and cultivars, whereas in the postcolonial period, cultural practices, pest control, and cultivar introduction have been the main focus. Crops receiving the most attention include cole crops (Brassica spp.), potato (Solarium tuberosum L.), tomato (Lycopersicon esculentum Mill.), pepper (Capsicum annuum L. ), onion (Allium spp. ), carrot (Daucus carota L.), bean (Phaseolus vulgaris L.), pea (Pisum sativum L.), squash (Cucurbita spp.), and melon [Cucumis melo L. and Citrullus lanatus (Thunb.) Matsum. \& Nakai].

Potatoes, cole crops, and carrots grow well in the highlands at $>1500 \mathrm{~m} \mathrm{ASL}$ and are eaten locally and exported. Research has been mainly directed toward cultivar evaluation, production methods, and pest and disease control.

Tomatoes and peppers are grown widely in medium- and low-elevation areas having warm climates. Several processing and fresh-market tomato cultivars have been tested, and some germplasm has been collected for breeding work. Selection for resistance to late blight and bacterial wilt is a major goal. Pepper research has emphasized cultivar adaptability and cultural practices.

Several onion cultivars have been grown successfully from the warm coastal areas to the cool highlands, as well as under irrigation in the hot, arid northern region. Trials on cultural practices, postharvest technology, and fungal disease control have been conducted, especially in the cool, humid areas. Researchers also are investigating seed production methods for the cool highlands.

Among the many leguminous vegetables, 
snap (French) bean is the most important. It is the number one export vegetable, with little local market appeal. The Grain Legume Project (GLP), based at the NHRS, has funded and organized most snap bean research, such as control of fungal and viral diseases and pests. Whereas the GLP has a breeding program for dry beans, snap bean cultivars were traditionally imported from the consumer countries for local testing, and no local breeding or seed production effort existed. Introducing, breeding, and improving beans are among the goals of the current bean program.

Many pea cultivars for freezing, canning, and the fresh market were planted in the highlands as early as 1932, and several cultivars were recommended, some of which are still grown. Until the late 1980s, research did not include other legumes, some of which are grown for export and grouped locally as "Asian" vegetables for export purposes. Similarly, many economically important cucurbit species have not been researched. Current plans, including breeding programs, cultural practices, and pest control methods, for developing these crops are underway.

Asparagus (Asparagus officinalis L.) is grown near Nairobi, mainly for export, and was among the early crops tested at Molo (1951-62). Research mainly looked at cultural practices such as spacing, fertilizer and manure application, cutting methods, and cultivar adaptability, resulting in the recommendation of several cultivars and cultural practices. Studies revealed that two cutting periods of 4 to 6 weeks each per year followed by replanting after $\approx 3$ years increased yield and reduced crown die-out.

\section{Ornamental}

A wide range of cut flowers, including carnation (Dianthus caryopyllus L.), rose (Rosa spp.), chrysanthemum [Dendranthema $\times$ grandiflorum (Ramat.) Kitamura], alstroemeria (Alstroemeria spp.), bells of Ireland (Moluccella laevis L.), statice(Limonium spp.), Star-of-Bethlehem (Ornithogalum arabicum L.), and orchid (Cymbidium spp., Cattleya spp., etc.), is grown in Kenya for export to Europe. Many are recent introductions (i.e., within the past 20 years). No documented research work, other than simple observations at the NHRS and Tigoni stations, exists for floricultural crops. Nor are there locally tested, standard recommendations for growing these crops. Production methods are borrowed from Europe or copied from neighbors who previously have succeeded in growing a particular crop. Current research efforts, therefore, are aimed at developing appropriate cultural practices.

The demand for ornamental plants has increased with urbanization and housing modernization efforts. Both tropical and TZ plants are grown as ornamentals, but, until recently, no documented research has been conducted in Kenya. The Kenyan nursery industry is new and small. There are few commercial nurseries, and they often produce only a few ornamental plants directly for local landscapers or government organizations. The few scattered fruit tree nurseries have no regular production schedules and chronically low inventories. Until recently, no inspection or certification service was in place, and, thus, assuring purchasers that they were receiving good-quality planting material was not possible. The limited research effort on nursery crops has centered on propagation methods, such as rooting ornamental plant cuttings and grafting or budding methods for major fruit crops. The new nursery registration service, which includes inspection and certification, is expected to stimulate research on nursery plants.

\section{Other crops}

Production of several other crops was attempted at the research stations, particularly Molo. Hop (Humulus lupulus L.) was imported from various countries in 1958-59 for mass selection, but the seedlings died even after treatment with plant-growth regulators (gibberellic acid and indole acetic acid), probably as a result of short photoperiods. Growing hops under supplemental lighting is being tested in the highlands near Egerton Univ., Njoro. Several Dioscorea spp. were tested in 1959-64 for extracting diosgenin, and some species yielded satisfactory quantities. Distilling oil from Pelargonium spp. was attempted in 1960-67 and resulted in reasonable yields. In 1962, Digitalis lanata J. F. Ehrh. produced low digoxin yields and grew poorly.

Pyrethrum [Chrysanthemum cinerariifolium (Trevir.) Vis.] was introduced into Kenya in 1928. The first commercial extraction $(4 \mathrm{t})$ occurred in 1932 and encouraged the rapid growth of this uniquely Kenyan industry. To support this growth, the Kenya Pyrethrum Growers Association (later the Pyrethrum Board of Kenya) was founded in 1933 to provide the necessary grading, inspection, quality maintenance, and marketing systems. A well-designed research program on pyrethrum has been underway since the early 1940 s at the Kenya Agricultural Research Institute's (KARI) Molo station. Research includes production methods, rapid propagation via tissue culture, crop protection, and breeding programs to improve pyrethrum yield and content. As a result, Kenya now grows and exports more than $90 \%$ of the world's pyrethrum.

\section{Current organization and prospects}

KARI was established in 1979 as part of the Ministry of Agriculture-Research Division. It is a semiautonomous institution responsible for strengthening the organization and management of Kenya's agricultural research. After the collapse of the East African Community (EAC) in 1977, KARI was charged with integrating the research activities of EAC and the government ministries. KARI was mandated, among other things, to conduct research in agriculture, veterinary medicine, and forestry; collaborate with other research institutions; and disseminate these research findings. In 1988, KARI took over all the public agricultural and livestock research stations.

Under KARI, the NHRS was mandated to coordinate the national horticultural research program. It also serves as the center for breeding priority horticultural crops and developing and testing production technologies. The fruit program emphasizes cultivar introduction and evaluation, pest and disease resistance, production of planting materials, and fruit usage. Priority crops include citrus, avocado, mango, macadamia, banana, passion fruit, and miscellaneous TZ fruits. Vegetable research concentrates on introducing, evaluating, and selecting suitable cultivars and developing technology for intensive small-scale production. Priority crops include tomato, cole crops, onion, carrot, and the Asian and indigenous vegetables. There are also special programs for beans and potatoes at the Thika and Tigoni research centers, respectively. Floricultural research initially was not a priority, but a program, now being developed at Tigoni, emphasizes cultivar introduction and evaluation, and development of cultural practices. Priority crops include carnation, rose, chrysanthemum, alstroemeria, statice, and Star-ofBethlehem. The horticultural crops production systems program emphasizes testing the viability of production technologies and improving productivity through integrated multidisciplinary farming systems approaches.

Horticultural research at Kenya's universities has been limited, because, until the early 1980 s, only one national university in Kenya (Univ. of Nairobi) and one nondegree college (now Egerton Univ.) had a horticulture program among their other agricultural programs. These programs emphasized training for extension workers; research was of secondary importance. Before the establishment of KARI, there was little or no coordination between the national research organization and academia, therefore, any work at the universities and colleges was independent of the national research process. Because of KARI's cooperative efforts with universities and colleges, two undergraduate and two graduate horticulture programs are offered at three of the four national universities.

Many horticultural species in Kenya are represented by a few old (often outdated) cultivars; indeed, some crops are often referred to by their cultivar name. In addition, many seeds, particularly vegetable and flower, are imported. Suitable new germplasm and adapted cultivars are needed for most crops. Research also is needed on suitable methods for producing seeds and other planting materials for vegetables, flowers, and fruits. These strategies would reduce the high cost of importing seeds and ensure production sustainability.

There are many indigenous wild and semiwild species that have potential economic value as fruits, vegetables, flowers, ornamentals, or medicinal plants. Some of these species were cultivated as recently as the 1960 s and showed great potential, but they now are considered weeds and in danger of being de- 
stroyed. Destroying this germplasm would be a long-term loss to Kenya and the world. Unfortunately, partly because of limited resources, present programs emphasize assisting projects that give immediate economic gains. Breeding programs to develop suitable cultivars of some indigenous species would assure sustainability of local production, and may encourage production overseas.

There is a growing interest in the application of biotechnology (mainly tissue culture) for the rapid multiplication of selected materials, disease indexing and elimination, and germplasm enhancement, conservation, and distribution. As biotechnology laboratories are developed and more scientists are trained, other more advanced biotechnology techniques could be tried. With the increased income from the horticultural industry and the general economic development of the country, more funds may become available to support horticultural research. KARI is expected to act as a liaison with other national and international centers to foster research and disseminate findings, thus improving research programs at the public centers and the universities.

\section{References}

Erez, A. 1980. Deciduous fruit growing in Kenya. Consultant Rpt. 2. Hors. Res. and Development Project, Food and Agr. Organization/United Nations Development Project/Ministry Agr., Kenya.

Gonzales, R.H. 1980. Integrated fruit tree pest control. Consultant Rpt. 3. Hort. Res. and DevelopmentProject,FoodandAgr.Organization/United Nations Development Project/Ministry Agr., Kenya.

Kabira, J.N. and J.M. Njoroge. 1984. Status of the potatoindustry in Kenya, p. 9-13. In: S. Nganga (cd.). Potato development and transfer of technology in tropical Africa. Intl. Potato Center, Nairobi.

Kenya Dept. of Agriculture. 1921-63, Dept. Agr. Annu. Rpts. Kenya Colony and Protectorate, GovernmentPrinter, Nairobi.

Kenya Ministry of Agriculture. 1964-67. Ministry Agr. Annu. Rpts. Republic of Kenya, GovernmentPrinter,Nairobi.

NationalHorticultureResearchStation.1987.GrowingofmacadamiainKenya. Natl. Hort. Res. Sta. Macadamia Project, Thika, Kenya.

Njuguna, S.K. 1987. The horticultural research in Kenya.Crop Science Dept., Egerton Univ. College, Njoro, Kenya.

Sharma, D.K. 1980. Improving mango production in Kenya. Consultant Rpt. no. 5. Hort. Res. and DevelopmentProject,Food and Agr. Organization/UnitedNationsDevelopmentProject/Ministry Agr., Kenya. 